\title{
Late recurrent iris synechia following laser goniopuncture for deep sclerectomy enhancement: case report
}

\author{
Sinéquia iriana tardia após goniopunctura a laser para esclerectomia profunda \\ não penetrante: relato de caso
}

Christiana Rebello Hilgert ${ }^{1}$, Guilherme Luz Hilgert ${ }^{2}$, Vinicius Andrighetto Hardoim ${ }^{3}$, Carlos Akira Omi ${ }^{4}$

\begin{abstract}
We report a case of recurrent iris synechiae one year after Nd:YAG laser goniopuncture for deep sclerectomy enhancement in the only functional eye of a patient with end-stage glaucoma. The possible pathophysiology of this uncommon complication and laser treatment aspects are discussed.
\end{abstract}

Keywords: Glaucoma; Laser therapy; Filtering, surgery; Iris diseases/etiology; Sclerostomy; Intraocular pressure; Case report; Humans; Female; Middle aged

\section{RESUMO}

A ocorrência de sinéquias irianas após goniopunctura a laser com finalidade de aumentar a filtração após esclerectomia não penetrante é evento raro e que pode levar à crise glaucomatosa aguda e suas consequências. Relatamos a ocorrência deste evento em olho único de paciente portadora de glaucoma em estágio final, um ano após a realização de goniopunctura. Os possiveis mecanismos fisiopatológicos desta complicação incomum, assim como aspectos do tratamento a laser para reverter o quadro são discutidos.

Descritores: Glaucoma; Terapia a laser; Cirurgia filtrante; Doenças da íris/etiologia; Esclerotomia; Pressão intraocular; Relatos de casos; Humanos; Feminino; Meia-idade

\section{INTRODUCTION}

Laser goniopuncture is a useful alternative to increase filtration and enhance the results of deep sclerectomy (DS) when the intraocular pressure rises due to increased resistance on the TrabecularDescemet membrane (TDM) and it is considered an efficient and safe procedure ${ }^{(1)}$. However, besides considered a low risk procedure, there are some potential complications that can impact the visual function of glaucomatous eyes. We report an unusual and recurrent complication one year after this procedure.

\section{CASE REPORT}

A 60-year-old pseudophakic Asian female presented with endstage primary open-angle glaucoma in her right eye and low vision in her left eye as sequelae of an old retinal detachment. The best corrected visual acuity was 20/40 in the right eye and light perception in the left eye. Her visual field and optic disc aspects are shown on figure 1. She underwent deep sclerectomy (DS) with mitomycin C in the right eye due to a persistent elevation in intraocular pressure (IOP) with maximum tolerated medications.

The procedure was uneventful. The external trabecular membrane was gently removed, the aqueous humor smoothly drained, and the conjunctiva was closed. On the first postoperative day, IOP was
$2 \mathrm{mmHg}$, a large and diffuse bleb was noted with no signs of inflammation or leakage. On the $30^{\text {th }}$ postoperative day, IOP increased to $8 \mathrm{mmHg}$ and remained so for the next four months.

On the $5^{\text {th }}$ postoperative month, the filtering bleb was slightly lower and IOP rose to $19 \mathrm{mmHg}$. UBM findings showed a hyper-reflectivity and increased thickness of the TDM (Figure 2), due to pigment deposition at the filtration site. Nd:YAG goniopuncture using free-running Q-switched mode with energy of $2.2 \mathrm{~mJ}$ was performed at TDM, until filtration was noted. IOP went down to $7 \mathrm{mmHg}$ immediately after the procedure and then decreased further to $2 \mathrm{mmHg}$ with the formation of a large and diffuse bleb. By the second month, IOP rose again to $8 \mathrm{mmHg}$. The patient was followed every other month for IOP control, which ranged from 6 to $8 \mathrm{mmHg}$ for about a year, with the presence of a diffuse and healthy filtering bleb. She also underwent argon laser retinal photocoagulation for a peripheral hole, and no signs of ocular hypotony or iris synechia on gonioscopy were noted during that period of time.

One year after goniopuncture, she presented with an acute glaucomatous crisis with severe ocular pain, nausea and vomiting for 2 days, after taking citalopram for treatment of depression. IOP was $45 \mathrm{mmHg}$ and gonioscopy revealed iris synechia and total obstruction of the filtration site. She was urgently prescribed intravenous mannitol, acetazolamide 500 mg, a fixed combination of timolol
Submitted for publication: October 7,2012

Accepted for publication: November 26, 2012

Study carried out at Instituto da Visão de Mato Grosso do Sul.

Physician, Departamento de Glaucoma, Instituto da Visão de Mato Grosso do Sul, Campo Grande (MS) - Brazil

2 Medical Student - UNIFENAS - Belo Horizonte (MG) - Brazil.

${ }^{3}$ Medical Student, Pontificia Universidade Católica de Sorocaba, Sorocaba (SP) - Brazil,

${ }^{4}$ Physician, Universidade Federal de São Paulo, Escola Paulista de Medicina, São Paulo (SP) - Brazil.
Funding: No specific financial support was available for this study.

Disclosure of potential conflicts of interest: C.R.Hilgert, None; G.L.Hilgert, None; V.A.Hardoim, None; C.A.Omi, None.

Correspondence address: Christiana Rebello Hilgert. Av. Rubens Gil de Camillo, 83 - Campo Grande (MS) - 79040-090 - Brazil - E-mail: c.hilgert@terra.com.br 


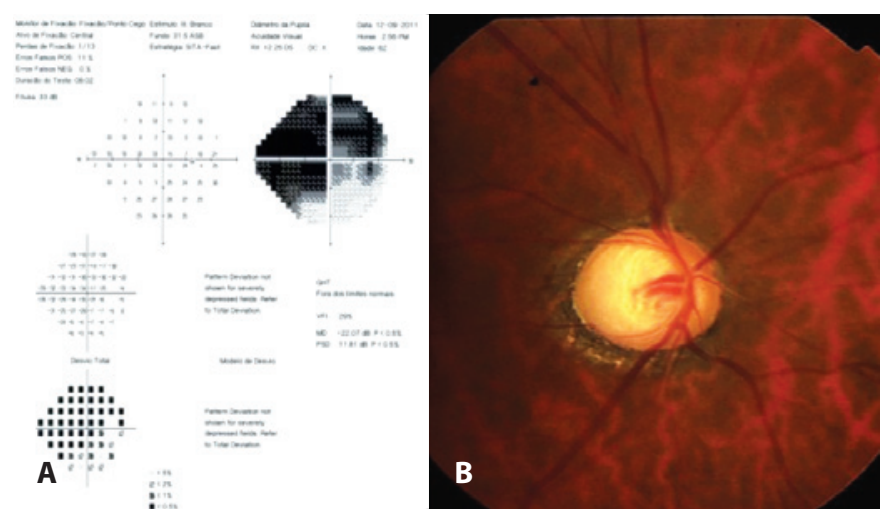

Figure 1. Severe visual field loss (A) and extensive optic nerve cupping (B) in the affected eye, prior to glaucomatous crisis.

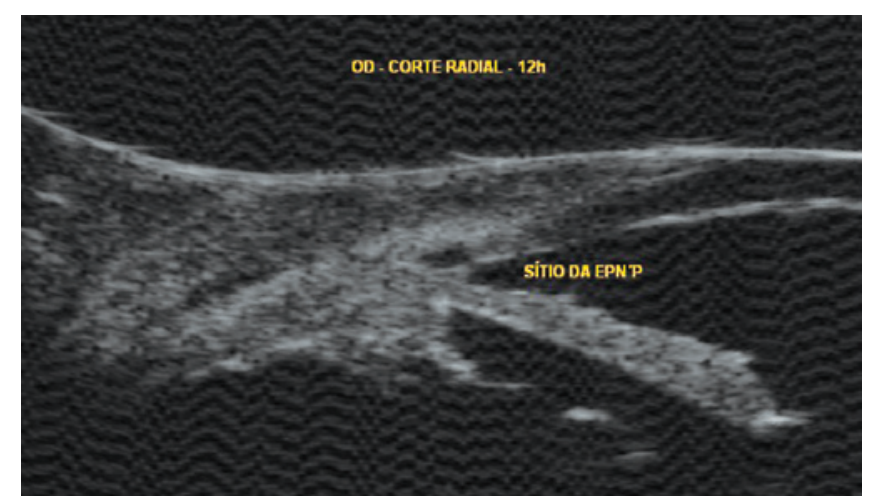

Figure 2. Hyperreflectivity and increased thickness of the Trabeculo-Descemet Membrane.

and dorzolamide, 2\% pilocarpine and latanoprost. IOP dropped to $18 \mathrm{mmHg}$ and $\mathrm{Nd}$ :YAG laser synechiolysis was performed to open the filtration site. A further drop in IOP to $6 \mathrm{mmHg}$ occurred with the formation of a large filtering bleb. On the next day, there was an additional drop in IOP to $2 \mathrm{mmHg}$, and after 2 weeks the IOP returned to the prior level of $8 \mathrm{mmHg}$.

In the following month, she went to a retina specialist and had her pupil dilated. After 2 days, she presented with another acute glaucomatous crisis with IOP levels returning to $45 \mathrm{mmHg}$. There was a total obstruction of the filtration site by peripheral iris. She was prescribed the same treatment regimen used for the first crisis and laser synechiolysis was repeated. Argon laser gonioplasty and $\mathrm{Nd}$ :YAG laser iridotomy were also performed to prevent a recurrent glaucomatous crisis. She underwent careful gonioscopy in the following days and weeks for the early diagnosis and treatment of possible recurrences. By day 3, the iris started to bulge at the surgery site again. Once again, synechiolysis and a more extensive gonioplasty were successfully performed (Figure 3 ). The IOP in the affected eye ranged from 8 to $9 \mathrm{mmHg}$ for the next 6 months. The final appearance of the anterior segment and filtering bleb is shown in figure 4. Although an excellent aqueous humor flow through the fistula was restored, maintaining a healthy filtering bleb, the patient lost 2 lines of visual acuity and had further restriction of the visual field, already seriously compromised.

\section{DISCUSSION}

Laser goniopuncture is a useful alternative to increase filtration when a high resistance to aqueous humor outflow on the TDM is
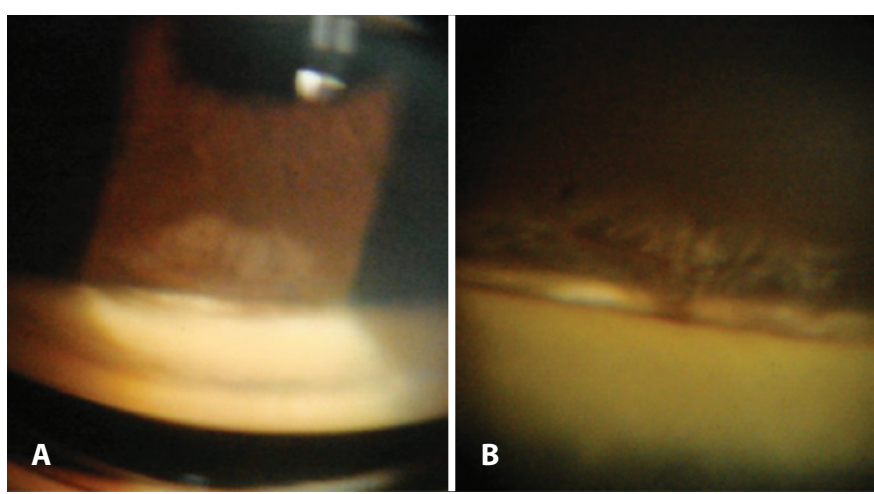

Figure 3. Argon laser iridoplasty and a smallYAG laser iridotomy were initially performed (A). Additional synechiolysis and more extensive argon laser gonioplasty were performed to avoid recurrences (B).
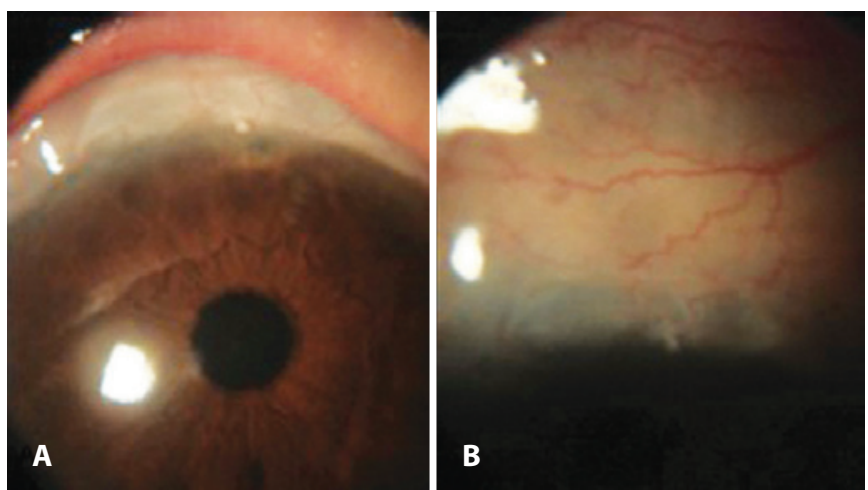

Figure 4. Final appearance of the anterior segment (A) and filtering bleb (B).

found. It is considered an efficient and safe procedure(1). Mermoud followed 41 patients for 2 years after laser goniopuncture and did not notice any case of iris synechia or iris prolapse ${ }^{(1)}$. Vuori first reported serious complications including synechia formation after goniopuncture in $10 \%$ of the patients who underwent the procedure ${ }^{(2)}$. More recently, others authors studied retrospectively 173 patients who had undergone laser goniopuncture and reported some complications after the procedure including $13.2 \%$ incidence of iris synechia in a total of 23 patients, but with a low incidence of late acute IOP rise (3 patients $-1.7 \%)^{(3)}$. There have been very few reports of synechia formation after laser goniopuncture ${ }^{(4,5)}$. However, once a hole is created on the TDM, this non-penetrating surgery becomes a penetrating filtering surgery with, unlike the trabeculectomy, the absence of a desired iridectomy, a procedure that could avoid iris prolapse and synechia formation. In such situations, these eyes are prone to acute glaucomatous crisis and all its consequences.

There is no formal advice in the literature examined to perform gonioplasty to flatten and lessen the thickness of the iris, and thereby avoid residual iris movements that could obstruct the surgery site. The Nd:YAG iridotomy necessary for that purpose should be more extensive than regularly performed, and a surgical approach would be more invasive and should be avoided when the filtering bleb shows no signs of fibrosis or failure.

We hypothesize that the smaller and more anterior goniopunctures could prevent severe hypotony. Hypotony itself following goniopuncture could also be a risk factor for that complication, since it can affect the humor aqueous dynamics, and in association with individual factors, such as iris lack of tonicity, or external factors, such as pupil dilation, it could favor unexpected 
iris bulging, iris synechia or iris prolapse followed by acute IOP rise, as in our case.

As far as we can tell, it is very appropriate to complement the goniopuncture with an extensive argon laser gonioplasty, especially in high risk cases as ours (severe glaucoma, only functional eye), since iris prolapse and synechia following the procedure, although uncommon, are potentially sight threating conditions. After goniopuncture and even in wide angles, the pupil dilation should be followed by a careful gonioscopy to study how the iris behaves in such situations, and if necessary, complementary pilocarpine drops or laser procedures should be performed to avoid glaucomatous crisis. These additional procedures should be evaluated further in future studies.

\section{REFERENCES}

1. Mermoud A, Karlen ME, Schnyder CC, Sickenberg M, Chiou AG, Hédiguer SE, et al. $\mathrm{Nd}$ :Yag goniopuncture after deep sclerectomy with collagen implant. Ophthalmic Surg Lasers. 1999;30(2):120-5.

2. Vuori ML. Complications of Neodymium:YAG laser goniopuncture after deep sclerectomy. Acta Ophthalmol Scand. 2003:81(6):573-6. Comment in: Acta Ophthalmol Scand. 2003;81(6):553-5

3. Anand N, Pilling R. Nd:YAG laser goniopuncture after deep sclerectomy: outcomes. Acta Ophthalmol. 2010;88(1):110-5.

4. Kim CY, Hong YJ, Seong GJ, Koh HJ, Kim SS. Iris synechia after laser goniopuncture in a patient having deep sclerectomy with a collagen implant. J Cataract Refract Surg. 2002;28(5):900-2

5. Qing G, Zhang S, Wang N. Recurrent iris prolapse after laser goniopuncture in an open-angle glaucoma patient treated with non-penetrating trabecular surgery. Eye (Lond). 2011;25(2):252-3. 